\title{
FRATURA POR ESTRESSE EM PACIENTE PORTADORA DE OSTEOGÊNESE IMPERFEITA: RELATO DE CASO
}

\section{STRESS FRACTURE IN OSTEOGENESIS IMPERFECTA CARRIER: A CASE REPORT}

\author{
Juliano Smaniotto Silveira ${ }^{*}$, Maria Vitória Moscardi Spack ${ }^{1}$, Roberto Márcio \\ Nogueira ${ }^{2}$, Reginaldo José Andrade ${ }^{3}$
}

\begin{abstract}
${ }^{1}$ Acadêmico do nono período do curso de Medicina da Faculdade Assis Gurgacz. ${ }^{2}$ Médico formado pela Universidade Federal de Pelotas, Ortopedista e Ortopedista pediátrico, docente do Centro Universitário Assis Gurgacz, ${ }^{3}$ Médico formado pela Universidade Federal do Paraná, Oncologista clínico e Hematologista, mestre em Medicina Interna e docente da Universidade Estadual do Oeste do Paraná e do Centro Universitário Assis Gurgacz.
\end{abstract}

*Autor correspondente: juliano296@gmail.com https://orcid.org/0000-0002-0034-1070

\begin{abstract}
RESUMO
Introdução: A osteogênese imperfeita é uma doença genética caracterizada por manifestações como fragilidade óssea e baixa densidade óssea. O tratamento depende da gravidade da condição, que é amplamente variável, e se baseia na reabilitação, fisioterapia, cirurgia ortopédica e em casos mais graves, o uso de bifosfonatos. Relato do caso: Paciente, sexo feminino, 22 anos, relatou dor em pé esquerdo há 14 dias, sem haver trauma. A radiografia de pé não mostrou alterações, mas a ressonância magnética revelou fratura por estresse no $2^{\circ}$ metatarso. Tem história pessoal e familiar de múltiplas fraturas e osteogênese imperfeita. Discussão: A paciente apresenta vários dos sintomas clássicos da doença, e apresentou fratura de estresse causada pela atividade física de caminhada, sem mecanismo de trauma. Conclusão: A fratura por estresse foi precipitada pela osteogênese imperfeita, e como a paciente apresenta poucos sintomas e densidade óssea normal, não foi necessário o uso de bifosfonatos.
\end{abstract}

Palavras-chave: Osteogênese imperfeita. Fratura por estresse. Fragilidade óssea.

\begin{abstract}
Introduction: Osteogenesis imperfecta is a genetic disorder characterized by manifestations like bone fragility and low bone mass. The treatment depends on the severity of the condition, which is largely variable, and is based on rehabilitation, physiotherapy, orthopedic surgery and in severe cases the use of bisphosphonates. Case Study: Patient, female, 22 years old, has been reporting left foot pain for the last 14 days, with no history of trauma. Radiography of the foot was normal, but a magnetic resonance showed a stress fracture on the $2^{\circ}$ metatarsal. She relates personal and familiar history of multiple fractures and osteogenesis imperfecta. Discussion: The patient have multiple classic symptoms of the disease, and presented a stress fracture caused only by walking, without trauma. Conclusion: The stress fracture was precipitated by osteogenesis imperfecta, and as the patient only presents mild symptoms and a normal bone density, the use of bisphosphonates was not necessary.
\end{abstract}

Keywords: Osteogenesis imperfecta. Stress fracture. Bone fragility. 


\section{INTRODUÇÃO}

A osteogênese imperfeita $(\mathrm{OI})$ é uma doença genética que causa diminuição da densidade e aumento da fragilidade óssea. A apresentação clínica da doença é variada, desde formas em que acontecem poucas fraturas até fraturas intrauterinas que levam à morte fetal. Manifestações clínicas extraósseas como escleras azuladas, dentinogênese imperfeita, hipermobilidade ligamentar e da pele, surdez e ossos intra-suturais em radiografias do crânio se associam a doença. (RAUCH \& GLORIEUX, 2004)

A doença é rara: a prevalência é de 1 em 200.000 indivíduos e a incidência é de aproximadamente 1 a cada 15.000 a 20.000 nascimentos. Não foi observada diferença em relação ao sexo e a raça. (SANTILI et al., 2005)

A OI é a desordem hereditária mais comum dos ossos e engloba um conjunto de causas genéticas que determinam os defeitos do colágeno, os defeitos em proteínas que processam o colágeno, os defeitos na diferenciação dos osteoblastos e os defeitos na mineralização óssea. A doença ocorre por mutações nos genes COL1A1 e COL1A2 principalmente, mas os avanços recentes demonstraram outros genes envolvidos, inclusive de caráter recessivo. (PATERSON, 1990; FORLINO \& MARINI, 2016)

O diagnóstico é clínico com grande importância para fraturas sem trauma ou com trauma de baixa energia e para a história familiar. Não há critérios diagnósticos mínimos e o quadro clínico típico, as manifestações extra-ósseas e a história familiar são importantes na definição. (SANTILI et al., 2005)

Não há cura para a Ol e o principal objetivo do tratamento é o manejo dos sintomas, aumentar a capacidade funcional, a autonomia e a mobilidade dos pacientes. É realizado prioritariamente pela fisioterapia, reabilitação e cirurgia ortopédica quando necessária. A prática de exercícios físicos é recomendada dentro dos limites do paciente para otimizar a mobilidade, o ganho de massa muscular (evitando atrofia) e a força. (RAUCH e GLORIEUX, 2004; ALHARBI, 2016) 


\section{RELATO DO CASO}

Paciente do sexo feminino, 22 anos, caucasiana, natural de Maringá e residente em Cascavel, Paraná, foi ao consultório de ortopedia com queixa de dor no pé esquerdo há 14 dias. A dor era em região do antepé esquerdo, de média intensidade, sem irradiação, dor mais intensa ao caminhar e apresentando melhora ao repousar. A paciente relatou que voltou a praticar atividades físicas (caminhada em esteira ergométrica) uma semana antes do início da dor, após longo período de sedentarismo.

$\mathrm{Na}$ história patológica pregressa, relatou história de 3 fraturas no pé direito. A paciente relatou também que teve baixa estatura na infância, e se fez necessário o uso de hormônio do crescimento (GH). Na história familiar seu pai, seus tios por parte de pai e sua irmã apresentam a doença e têm história de múltiplas fraturas. O diagnóstico clínico de Ol foi realizado após a primeira fratura, que ocorreu sem mecanismo de trauma, aliado às escleras azuladas e à história familiar.

Paciente se apresentou em bom estado geral e com marcha claudicante à ectoscopia. Escleras azuladas e hipermobilidade ligamentar foram evidenciadas ao exame físico. A dentinogênese era normal e não foram observadas deformidades ósseas. A estatura da paciente era normal.

Figura 1 - Radiografia de antepé esquerdo, sem alterações.

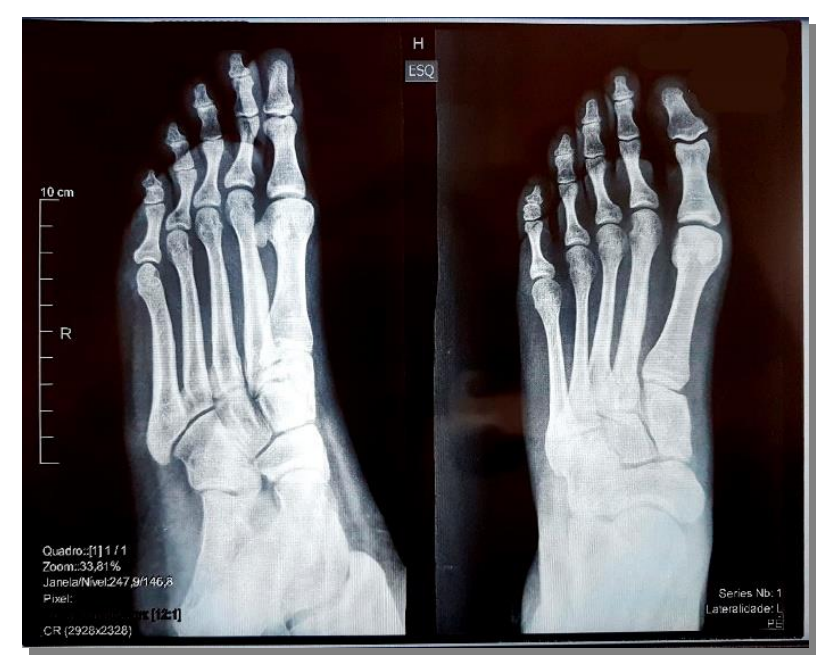


O pé esquerdo da paciente não apresentava edema, equimoses, hematomas ou deformidades locais. Não havia dor à palpação. Pulsos poplíteo, tibial posterior e pedioso eram normais e simétricos. A radiografia do pé esquerdo (figura 1) não demonstrou alterações. Paciente foi orientada a utilizar um anti-inflamatório não esteroidal (AINE), a aplicar gelo no local e a adotar cuidados gerais. Após 9 dias de tratamento, com persistência de dor, retornou para nova consulta. A ressonância magnética $(R M)$ do pé foi realizada, e identificou fratura por estresse no $2^{\circ}$ metatarso (figura 2). Densitometria óssea demonstrava densidade mineral óssea da coluna lombar normal, do colo do fêmur normal mas no limite inferior à osteopenia e do fêmur total normal. A paciente recebeu tratamento com AINE oral, complexo vitamínico (incluindo colecalciferol), carbonato de cálcio e fez uso de bota ortopédica imobilizadora por 3 meses.

Figura 2 - RM de antepé esquerdo demonstrando fratura distal do $2^{\circ}$ metatarso e pequeno edema perilesional (seta vermelha).

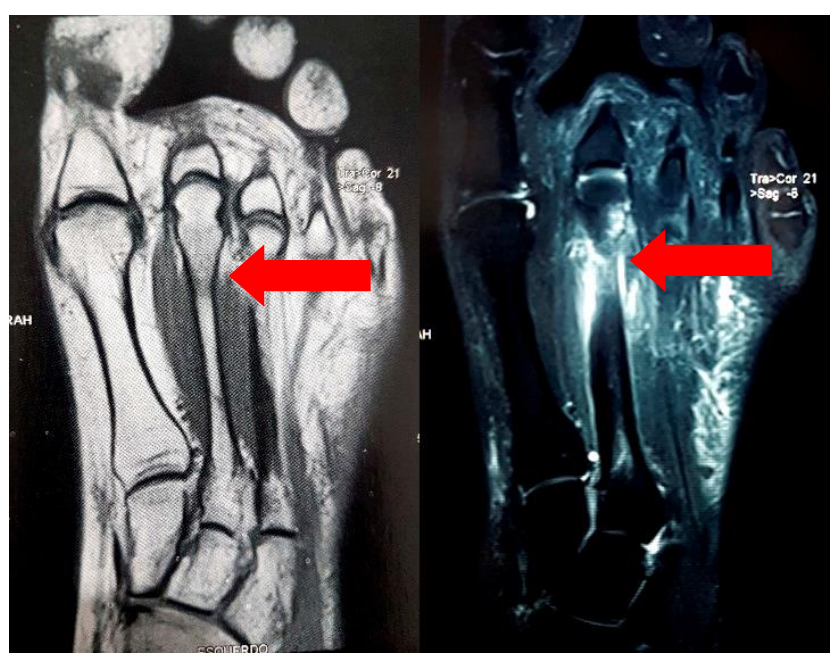

Radiografia e RNM de pé esquerdo realizados 3 meses após, demonstraram fratura do $2^{\circ}$ metatarso em consolidação. Paciente foi orientada a manter o carbonato de cálcio e colecalciferol. A reavaliação após 9 meses, identificou que a fratura estava consolidada (ressonância magnética) e que a densidade óssea era normal (densitometria). Paciente foi orientada a realizar atividades físicas de baixo impacto e a seguir em uso de carbonato de cálcio e colecalciferol. 
Figura 3 - RM de controle demonstrando fratura distal do $2^{\circ}$ metatarso em consolidação (seta vermelha).

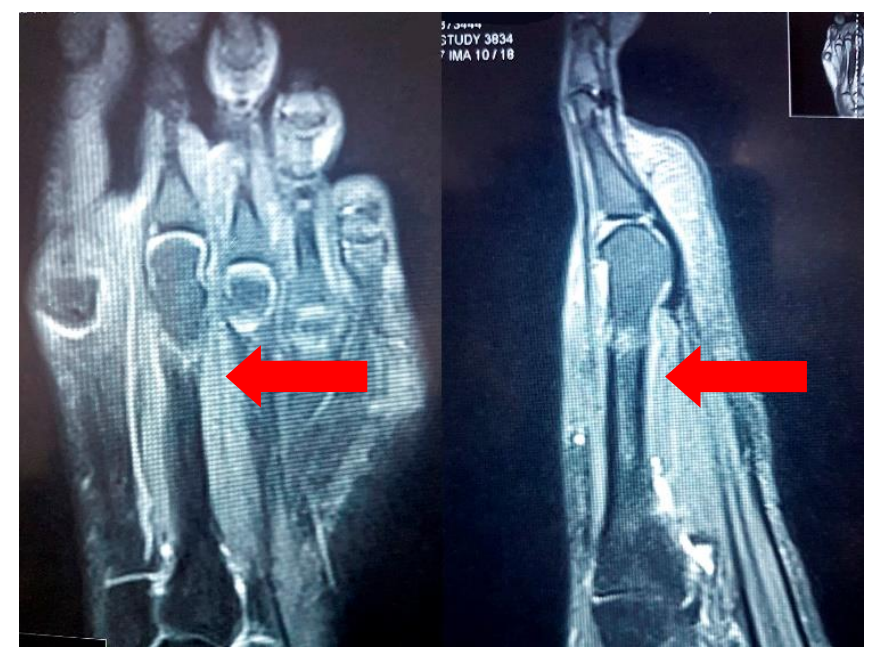

\section{DISCUSSÃO}

A principal característica da Ol é a fragilidade óssea, devido à diminuição da densidade mineral óssea, causando fraturas e malformações. Outros sinais e sintomas como escleras azuladas, hipermobilidade cápsulo-ligamentar e da pele, ossos intra-suturais em radiografias do crânio e surdez podem estar presentes no quadro clínico da doença (RAUCH e GLORIEUX, 2004).

A OI possui formas autossômicas dominantes e recessivas. Mais de $90 \%$ dos casos acontecem por um defeito nos genes COL1A1 e COL1A2, responsáveis pela codificação da cadeia a tipo 1 e da cadeia a tipo 2, respectivamente, e que são de herança autossômica dominante (STUBBE, PRIMORAC e HÖPPNER, 2017). Estas cadeias compõem o colágeno tipo 1, que é a proteína estrutural mais abundante dos ossos, da pele e da matriz extracelular dos tendões. Sete formas recessivas foram identificadas, que causam mutações em genes que codificam proteínas e interagem com 0 colágeno em seu dobramento, ou modificações pós-traducionais. Outras duas mutações afetam a mineralização dos ossos e também diminuem a produção de colágeno. Outros três genes, que quando mutados, causam defeitos na diferenciação dos osteoblastos e deficiência de colágeno (FORLINO \& MARINI, 2016).

Forlino e Marini (2016), classificaram a Ol em tipos segundo cada gene específico mutado, e agruparam estes tipos em cinco grupos conforme a 
principal alteração resultante das mutações, porém, devido à grande complexidade genética e fenotípica da Ol, tornou-se impossível manter a correlação entre estes muitos tipos e a clínica. Por este motivo, o Nosology Group of the International Society of Skeletal Dysplasias, em 2010, recomendou a classificação baseada no quadro clínico e na gravidade da doença (FORLINO \& MARINI, 2016; VALADARES et al., 2014; WARMAN et al., 2010).

O tipo I é a forma menos grave da doença: a estatura é normal ou pouco reduzida, as escleras são azuladas e não há dentinogênese imperfeita (RAUCH e GLORIEUX, 2004). A doença do tipo II é a forma mais grave: há fraturas intrauterinas múltiplas (predominando em costelas e ossos longos) e a morte ocorre no período neonatal: 60\% morrem nas primeiras 24 horas e $80 \%$ não sobrevivem ao primeiro mês de vida. Esse tipo também é conhecido como letal perinatal (ANTONIAZZI et al., 2000).

A doença de tipo III também é grave: os pacientes apresentam estatura muito baixa, face triangular, escoliose grave, escleras azuladas e dentinogênese imperfeita (RAUCH e GLORIEUX, 2004).

O tipo IV é moderado e heterogêneo, não sendo tão característico quanto aos outros tipos. As fraturas geralmente ocorrem na infância, mas podem ocorrer ainda na fase intrauterina; a altura pode ser normal ou significativamente baixa e a dentinogênese imperfeita pode ou não estar presente (RUSH, 2019). O tipo $\checkmark$ é caracterizado radiologicamente pela calcificação da membrana interóssea dos antebraços e pela formação de calos ósseos hiperplásicos após fraturas ou procedimentos cirúrgicos, característica patognomônica deste tipo. Os pacientes não apresentam escleras azuladas nem dentinogênese imperfeita (VALADARES et al., 2014; CHEUNG, GLORIEUX, e RAUCH, 2007). A Ol da paciente foi classificada como tipo I, pois se apresentava de forma leve, com escleras azuladas e estatura reduzida. A dentinogênese imperfeita não foi observada. O diagnóstico da doença tem como base a clínica. Não há critérios mínimos e a história familiar e fraturas típicas são de grande importância. Fraturas aparentemente espontâneas, devem ser levadas em consideração, principalmente em sujeitos com a estrutura musculoesquelética normal. (SANTILI et al., 2005). A ocorrência de fraturas em traumas de baixa energia ou 
até mesmo sem trauma é uma característica importante da Ol e de outras desordens ósseas. As fraturas não estão sempre associadas aos sinais típicos, como edema e contusão local. Os pacientes também podem apresentar achados incidentais de fraturas em diversos estágios de consolidação (PATERSON, 1990).

As fraturas por estresse são o resultado final de sucessivas sobrecargas cíclicas sobre o osso, que acabam causando microfraturas no trabeculado ósseo. A carga aplicada não seria suficiente para causar uma lesão imediata, porém após contínuas repetições e tempo inadequado para o remodelamento ósseo, começam a ocorrer microfraturas que sem o tratamento adequado resultarão na fratura do local acometido. O reparo deste tipo de fratura é diferente do reparo das demais fraturas agudas, pois ocorre exclusivamente pelo remodelamento ósseo, com a reabsorção de células danificadas e substituição por células novas (ASTUR et al., 2016). A fratura por estresse da paciente ocorreu sem mecanismo de trauma, apenas com atividades físicas de baixa intensidade, precipitada pela OI. Fragilidade óssea foi demonstrada e se enquadra em um importante aspecto da desordem. Não foram observados no exame físico sinais típicos de fratura: à inspeção não havia edema ou contusão local e dor a palpação.

Os sintomas extraósseos devem ser utilizados com cuidado para auxiliar na definição, pois as escleras azuladas se apresentam tipicamente em crianças sem a condição, e em apenas $2 / 3$ dos pacientes com Ol. A dentinogênese imperfeita é mais comum nos dentes decíduos do que nos permanentes e está presente em metade dos pacientes portadores da condição. A hipoacusia é comum a partir da $3^{\underline{a}}$ década de vida. O diagnóstico é dificultado em pacientes que mesmo apresentando características clínicas clássicas, não têm história familiar e anormalidades extraósseas características da doença. Isso também ocorre porque não existem critérios diagnósticos bem estabelecidos (RAUCH e GLORIEUX, 2004; PATERSON, 1990).

No caso relatado, o diagnóstico de Ol foi realizado na infância motivado por um conjunto de fatores: a paciente sofreu fratura sem mecanismo de trauma e possuia escleras azuladas, histórico familiar para a doença e histórico de baixa estatura na infância com necessidade de uso de GH. 
Exames complementares como a radiografia, a densitometria óssea e a tomografia da coluna lombar são métodos que podem facilitar o diagnóstico. $\mathrm{Na}$ radiografia visualiza-se uma redução do trabeculado ósseo normal, diminuição da espessura cortical e deformidades angulares (principalmente em ossos longos de membros inferiores). A densitometria óssea quantifica objetivamente a diminuição da massa óssea e é superior à radiografia na avaliação dos casos (SANTILI et al., 2005). A avaliação genética ou o estudo quantitativo e qualitativo do colágeno tipo 1 ajuda a esclarecer o diagnóstico. O estudo genético identifica 90\% dos pacientes: o resultado negativo, contudo, não exclui o diagnóstico (RAUCH e GLORIEUX, 2004).

O tratamento da Ol é baseado na reabilitação, na fisioterapia e nas cirurgias ortopédicas, visando melhorar a mobilidade e as capacidades funcionais. O exercício físico deve ser estimulado dentro dos limites do paciente (considerando o risco de fraturas) para estimular a musculatura, evitando a perda óssea e contraturas musculares (RAUCH e GLORIEUX, 2004).

O tratamento medicamentoso é realizado com bifosfonatos, que reduzem a atividade osteoclástica, aumentam a densidade óssea e previnem deformidades da coluna vertebral. Há melhora na qualidade de vida, com importante diminuição da dor e melhora das atividades diárias. A decisão de iniciar o uso dos bifosfonatos depende da gravidade da doença, da idade do paciente e de sua capacidade de controlar o uso via oral ou via endovenosa (ÅSTRÖM e SÖDERHÄLL, 2002; MARR, SEASMAN e BISHOP, 2017).

Outro medicamento que mostrou eficácia em estudos recentes é o neridronato, um aminobifosfonato que demonstrou rápido aumento da densidade mineral óssea em crianças em crescimento e uma redução de $64 \%$ no número de fraturas. Os resultados são similares em crianças recém nascidas com menos de 1 ano de idade afetados pelas formas mais graves da doença. Em adultos foi demonstrada redução na taxa de fraturas. O grande benefício em relação ao pamidronato (principal bifosfonato) é a redução do tempo de hospitalização. Outros medicamentos ainda estão em fase de estudos e precisam de mais dados para confirmar sua eficácia (ALHARBI, 2016). 
O paciente deve ser avaliado para decidir o melhor tratamento para cada caso. No tratamento do tipo I o foco é que o paciente viva uma vida normal, reduzindo o risco de fraturas e aumentando a densidade óssea. O cuidado é mais direcionado às fraturas eventuais, que devem ser tratadas como as fraturas de pacientes sem a condição, à perda auditiva e a baixa estatura. Estes pacientes devem ser encorajados a viver uma vida normal, apenas evitando atividades e esportes com risco de impacto (ANTONIAZZI et al., 2000).

Pacientes com a forma grave da doença (tipo II) devem ser avaliados e submetidos a procedimentos para o manejo de insuficiência respiratória. A insuficiência cardiorespiratória e as infecções respiratórias são as principais causas de morte. Apenas algumas crianças conseguem deixar o hospital e estas necessitam de cuidados domicilares especiais. (ANTONIAZZI et al., 2000).

Os cuidados nos primeiros meses de vida devem ser redobrados nos pacientes com doença classificada em tipos III e IV, com o objetivo de reduzir deformidades da coluna vertebral, aumentar a mobilidade e proporcionar mais autonomia aos pacientes. O atendimento deve ser multidisciplinar, o que envolve vários campos de atuação: pediatria, especialistas em ortopedia, fisioterapeutas e enfermeiros, a família do paciente e até mesmo a comunidade. Procedimentos cirúrgicos e o emprego de bifosfonatos são mais frequentes e úteis (ANTONIAZZI et al., 2000).

No caso relatado a reabilitação da paciente foi realizada com o uso de bota imobilizadora ortopédica, visando recuperar a capacidade funcional. A paciente não necessita do uso dos bifosfonatos, pois é portadora de Ol do tipo I. Foi observado na primeira densitometria óssea que, a densidade mineral óssea do colo do fêmur era limítrofe entre o normal e a osteopenia. Depois da utilização de carbonato de cálcio e colecalciferol, nova densitometria demonstrou densidade normal.

\section{CONCLUSÃO}

Este relato abordou e estudou uma importante condição clínica, a osteogênese imperfeita, e revisou os principais sintomas, sinais e características da doença, observando-se no caso diversos deles, como a fragilidade óssea, as 
fraturas com trauma de baixa energia ou sem trauma, as escleras azuladas e a hipermobilidade ligamentar.

Foi possível observar também que a fratura ocorreu precipitada pela doença como resultado de atividade física de baixa intensidade, na ausência de trauma. A história familiar foi importante para o diagnóstico, pois sua ausência dificulta a definição da condição. O principal tratamento, baseado na reabilitação do paciente, foi realizado com o uso de bota imobilizadora ortopédica, que resultou em consolidação da fratura após 9 meses de acompanhamento.

\section{REFERÊNCIAS}

ALHARBI, SAMIR ABDULKARIM. A Systematic Overview of Osteogenesis Imperfecta. Molecular biology, v. 05, n. 01, 2015. https://doi.org/10.4172/2168-9547.1000150

ANTONIAZZI, FRANCO, MOTTES, MONICAFRASCHINI, PAOLO et al. Osteogenesis Imperfecta. Paediatric Drugs, v. 2, n. 6, p. 465-488, 2000.

ASTROM, E. Beneficial effect of long term intravenous bisphosphonate treatment of osteogenesis imperfecta. Archives of Disease in Childhood, v. 86, n. 5, p. 356-364, 2002. https://doi.org/10.1136/adc.86.5.356

ASTUR, DIEGO COSTA, ZANATTA, FERNANDOARLIANI, GUSTAVO GONÇALVES et al. Fraturas por estresse: definição, diagnóstico e tratamento. Revista Brasileira de Ortopedia, v. 51, n. 1, p. 3-10, 2016. https://doi.org/10.1016/j.rbo.2015.02.002

CHEUNG, MOIRA S, GLORIEUX, FRANCIS HRAUCH, FRANK. Natural History of Hyperplastic Callus Formation in Osteogenesis Imperfecta Type V. Journal of Bone and Mineral Research, v. 22, n. 8, p.1181-1186, 2007. https://doi.org/10.1359/jbmr.070418

FORLINO, ANTONELLA MARINI, JOAN C. Osteogenesis imperfecta. The Lancet, v. 387, n. 10028, p. 1657-1671, 2016. https://doi.org/10.1038/nrdp.2017.52

MARR, CAROLINE, SEASMAN, ALISONBISHOP, NICK. Managing the patient with osteogenesis imperfecta: a multidisciplinary approach. Journal of Multidisciplinary Healthcare, v. Volume 10, p. 145-155, 2017. https://doi.org/10.2147/JMDH.S113483

PATERSON, C R. Osteogenesis Imperfecta and other Bone Disorders in the Differential Diagnosis of Unexplained Fractures. Journal of the Royal Society of Medicine, v. 83, n. 2, p. 72-74, 1990. https://doi.org/10.1177/014107689008300205

RAUCH, FRANK GLORIEUX, FRANCIS H. Osteogenesis imperfecta. The Lancet, v. 363, n. 9418, p. 1377-1385, 2004. https://doi.org/10.1016/S0140-6736(04)16051-0

RUSH, E. Genetics of Osteogenesis Imperfecta: Background, Pathophysiology, Epidemiology. Emedicine.medscape.com. Disponível em: <https://emedicine.medscape.com/article/947588-overview>. Acesso em: 7 out. 2019. 
SANTILI, CLÁUDIO, AKKARI, MIGUELWAISBERG, GILBERTO et al. Avaliação clínica, radiográfica e laboratorial de pacientes com osteogênese imperfeita. Revista da Associação Médica Brasileira, v. 51, n. 4, p. 214-220, 2005. http://doi.org/10.1590/S0104-42302005000400018

STUBBE A, PRIMORAC D, HOPPNER W. Molecular genetics analysis of osteogenesis imperfecta in clinical practice. Paediatria Croatica. 2017;61(3):141-146 https://doi.org/10.13112/PC.2017.21

VALADARES, EUGÊNIA R., CARNEIRO, TÚLIO B.SANTOS, PAULA M. et al. What is new in genetics and osteogenesis imperfecta classification?. Jornal de Pediatria, v. 90, n. 6, p. 536-541, 2014. http://doi.org/10.1016/j.jped.2014.05.003

WARMAN, MATTHEW L., CORMIER-DAIRE, VALERIEHALL, CHRISTINE et al. Nosology and classification of genetic skeletal disorders: 2010 revision. American Journal of Medical Genetics Part A, v. 155, n. 5, p. 943-968, 2011. https://doi.org/10.1002/ajmg.a.33909 